\title{
Nem leigos nem peritos: o semeador e as mudanças climáticas no Brasil.
}

\author{
Pedro Henrique Campello Torres ${ }^{2}$ \\ Pedro Roberto Jacobi ${ }^{3}$ \\ Ana Lia Leonel ${ }^{4}$
}

\section{Resumo}

A agenda das mudanças climáticas e suas relações com lutas e mobilizações sociais tem crescido nas últimas décadas em escala global. No campo sociológico, o tema tem recebido interesse crescente, tanto em sua produção científica como no engajamento social. A partir de levantamento da produção sociológica brasileira em periódicos nacionais, buscou-se verificar como esse processo está em andamento no Brasil. Em seguida, buscando refletir sobre a relação entre a produção científica e a mobilização das ruas, analisam-se, de forma comparativa, as manifestações da greve climática ocorridas em setembro de 2019. Tanto a produção acadêmica quanto a mobilização social foram extremamente pouco representativas no caso analisado.

Palavras-chave: Mudanças climáticas. Antropoceno. Greve pelo clima. Fridays for future. Justiça climática.

\section{Introdução}

Ao passo que eventos climáticos severos passam, cada vez mais, a fazer parte da realidade das cidades e seus residentes - com a tendência a tornarem-se ainda mais frequentes (AMBRIZZI, et al., 2017) -, aumenta

1 Agradecemos à Fundação de Amparo à Pesquisa do Estado de São Paulo (Fapesp), processos 2018/06685-9, 2015/03804-9, 20 19/05644-0, 2018/02464-8 e 2019/18462-7. Agradecemos à Beatriz Pereira Silva pelo apoio fundalmental na coleta de dados e informações para a presente pesquisa.

2 Pesquisador do Instituto de Energia e Ambiente (IEE), Universidade de São Paulo (USP). E-mail: pedrotorres@ usp.br. https://orcid.org/0000-0002-0468-4329

3 Professor Titular Sênior no Programa de Pós-Graduação em Ciência Ambiental (Procam), Instituto de Energia e Ambiente (IEE), Universidade de São Paulo (USP). https://orcid.org/0000-000I-6I43-3019

4 Doutoranda em Planejamento e Gestão do Território (PGT), na Universidade Federal do ABC (UFABC). https:// orcid.org/0000-0003-4914-143X

\section{$(\mathrm{cc}) \mathrm{Br}$}

Direito autoral e licença de uso: Este artigo está licenciado sob uma Licença Creative Commons. Com essa licença você pode compartilhar, adaptar, para qualquer fim, desde que atribua a autoria da obra, forneça um link para a licença, e indicar se foram feitas alterações. 
a percepção da necessidade de açóes concretas de planejamento e governança para se enfrentar as mudanças climáticas. Aprender com as tragédias têm sido mote frequente nos discursos políticos pós-desastres ambientais no Brasil, o que não tem significado, na prática, melhores gestóes para preveni-los (NOGUEIRA; CANIL, 2018; SULAIMAN; ALEDO, 2016).

Tragédias e crises podem compor o que Kingdon (1995) considera como uma "janela de oportunidade" para uma mudança de paradigma em relação às políticas públicas. Quanto aos pós-desastres, não é o que tem se verificado no Brasil em eventos recentes, como o Ciclone Catarina (MARCELINO et al., 2005), os deslizamentos e enchentes na regiáo serrana do Rio de Janeiro (COATES, 2019) e na região do ABC paulista (TRAVASSOS et al., 2020), entre tantos outros casos recentes.

Do ponto de vista dos processos de aprendizagem e articulação de saberes para a gestão da adaptação às mudanças climáticas, as instituiçóes públicas, bem como a academia, são cada vez mais desafiadas a irem além da abordagem convencional top-down e assumirem uma filosofia de aprendizagem mútua (ADGER; ARNELL; TOMPKINS, 2005). Nesse contexto, emergem modelos participativos, como a pesquisa-ação, bem como os conceitos da coproduçáo de conhecimento (SCHMIDT; GOMES; JACOBI, 2019).

No entanto, a implementação dessa agenda não é clara e a extensão de um redirecionamento de resposta da produção de conhecimento em Ciências Sociais, mais especificamente na sociologia, é ainda marginal, embora ascendente, dentro de seu próprio campo disciplinar. Não se trata aqui de uma reflexão sobre qual o papel da sociologia nesse processo, o que já foi feito por Ferreira (2004), Yearley (2009), Urry (2009), Brulle e Riley (2015), entre outros. O objetivo aqui é duplo e interconectado. De um lado, refletir sobre como o campo da sociologia no Brasil tem trabalhado a questão, a partir da produção científica em periódicos nacionais de maior excelência de acordo com a Coordenação de Aperfeiçoamento de Pessoal de Nível Superior (Capes). Por outro lado, analisar como a conjuntura do Brasil, e sua articulação como país do Sul Global, reverbera no aumento do engajamento da sociedade civil sobre o tema. 
No clássico quarto capítulo de Raizes do Brasil (HOLANDA, 2006), "Semeador e Ladrilhador", Holanda apresenta sua tese de que o mundo colonial ibérico pode ser dividido nos dois tipos ideais homônimos do título, referindo-se à América portuguesa e hispânica, respectivamente. Em nosso caso, o Semeador seria o homem do mundo colonial do tipo aventureiro, com audácia de ganho imediato. A particularidade brasileira - extensão do mundo português - ainda estaria apoiada em um modelo de produção com latifúndio monocultor e trabalho escravo. Na outra dimensão territorial da América, a Espanha é a inspiração direta e o território regido pelas leis do El Rey. O planejamento das cidades se dá pela construção do quadrilátero da praça maior e das ruas lineares. O que não se verificaria aqui ${ }^{5}$ seria o Ladrilhador, povoador e trabalhador.

A alusão ao semeador aqui se faz para iluminar as açóes, ou motivaçóes de profissionais, especialistas ou náo especialistas, nem leigos nem peritos que hoje no Brasil têm trabalhado no campo da práxis com adaptação às mudanças climáticas no campo e na cidade. Muitas vezes sem formação, equipamento e equipe necessária, reage mais do que planeja ou se antecipa aos impactos e efeitos de eventos severos (UITTO; VAN DEN BERG; PURI, 2017; JACOBI et al., 2013; BARBI; FERREIRA, 2013, JACOBI; MOMM-SCHULT; BOHN, 2013).

O objetivo é contribuir com a reflexão sobre o porquê de a agenda tanto da produção acadêmica sociológica quanto das mobilizaçóes sociais sobre clima ainda ser tão breviloquente no Brasil. Trata-se, portanto, de apresentar uma fotografia de um extrato do campo sociológico buscando entender as relaçóes - ou suas ausências - sobre o que se produz na academia e as mobilizaçôes sociais sobre o tema.

\section{Métodos}

O artigo está dividido, portanto, em duas partes. A primeira parte busca desvendar como a produção sociológica nas revistas brasileiras tem

5 O argumento é pensado para justificar a separação das categorias em tipos ideais weberianos: Ladrilhador $x$ Semeador. No entanto, é questionável a compreensão da formação das cidades coloniais brasileiras com a ausência de planejamento (sobretudo em relação à primeira capital, Salvador) realizada à sorte de um tipo aventureiro de homem. Sobre o assunto, é importante a contribuição de Riserio (2012). 
se referido à questão das mudanças climáticas, para isso foi realizado um levantamento nos principais periódicos nacionais com extrato Qualis Capes A1 (18) ou A2 (31) na área de Sociologia - base 2013-2016. Foram excluídas revistas internacionais que constam no Qualis. Foi levantado um total de 49 periódicos, em que foi realizada a verificação da ocorrência do descritor "Mudanças Climáticas" + "Antropoceno" em todas as versôes disponíveis para consulta on-line dos periódicos publicados até 2018.

Náo se trata aqui de entender os resultados desse levantamento como definidores do campo da sociologia brasileira. Ao contrário, reconhece-se que tais procedimentos podem apresentar nebulosas na produçáo de saberes do campo, como, por exemplo, os autores brasileiros que têm publicado em periódicos internacionais não indexados pela $\mathrm{Capes}^{6}$, assim como o caso de periódicos interdisciplinares, mas com escopo claramente aberto ao diálogo e contribuição ao campo sociológico com questóes ambientais, como clima e o antropoceno ${ }^{7}$. Dois exemplos que merecem o registro são as revistas Ambiente \& Sociedade (Qualis B2 para Sociologia) e Desenvolvimento e Meio Ambiente (Qualis B3 para Sociologia).

Trata-se, portanto, de apresentar uma fotografia de um extrato do campo, sendo o objetivo principal dessa operação a busca pelo entendimento entre o que se produz na academia e as mobilizaçóes sociais sobre o tema. Na segunda parte do artigo, após a análise e discussão dos resultados do levantamento bibliográfico, foi realizada uma comparação entre as recentes manifestações ocorridas com a pauta das mudanças climáticas em setembro de 2019 no Brasil e em outros países. O objetivo de tal comparação, para além de iluminar as diferenças, é contribuir com a reflexão sobre o porquê de a agenda de mobilizaçóes sociais sobre clima ainda náo possuir contornos identitários próprios, alinhados com uma agenda local de desigualdades e vulnerabilidades sociais em nosso país.

6 A publicação Environmental Sociology, por exemplo, editada pelo RC24, Grupo de Pesquisa em Ambiente e Sociedade da International Sociology Association, não está indexada no Qualis Capes, assim como o periódico Environmental Justice, embora tenha impact factor maior que muitos periódicos indexados como Qualis A.

7 Para um maior aprofundamento sobre o tema, ver: "O Sistema Internacional no Antropoceno", de Eduardo Viola e Larissa Basso (2016, p. I-18), e O Antropoceno e a ciência do sistema terra, e José Eli da Veiga (2019). 


\section{Produção científica sobre mudanças climática e a época do Antropoceno em periódicos nacionais de sociologia}

Foram encontrados 18 artigos com menção a "Mudanças Climáticas" + "Antropoceno". Outros descritores próximos apareceram na busca, como Antropocêntrica (30), Antropocentrismo (35), Antropocêntrico (31). Porém, quando verificados junto com o descritor "Mudanças Climáticas", percebe-se que tais artigos não discutem sobre a temática ambiental e climática.

Esses 18 artigos estáo presentes em nove periódicos, como pode ser observado na Figura 1. A Revista Estudos Feministas é a que aparece com o maior número de artigos listados, com cinco publicaçóes, seguida pela $R e-$ vista de Antropologia, com três artigos, Horizontes Antropológicos, História, Ciências, Saúde, e Contemporânea, com dois artigos. As demais possuem apenas uma contribuição.

O ano de 2017 é o que tem maior número de artigos, com um total de seis, seguido por 2015, com quatro, 2014 e 2016, com três, e 2018, com dois. Vale destacar, no entanto, que um dos motivos para que 2017 tenha o maior número de artigos é a organização de um dossiê na Revista Estudos Feministas, pois, dos seis artigos de 2017, quatro estão nesse periódico.

Entre os 18 artigos, dois se destacam pelo número de citaçôes registradas na base do Google Scholar, são eles "Governança ambiental e economia verde", com 55 citaçóes, e "Para distinguir amigos e inimigos no tempo do Antropoceno", com 50. O terceiro com maior número de citaçóes, com 27, intitula-se "Feminismos descoloniais para além do humano". A partir do quarto com mais mençóes, "Uma antropologia além de natureza e cultura?", com nove citaçóes, o número de citaçóes cai consideravelmente, como pode ser observado na Tabela 1 . 
Nem leigos nem peritos: o semeador e as mudanças climáticas no Brasil | Pedro Henrique Campello Torres, Pedro Roberto Jacobi, Ana Lia Leonel

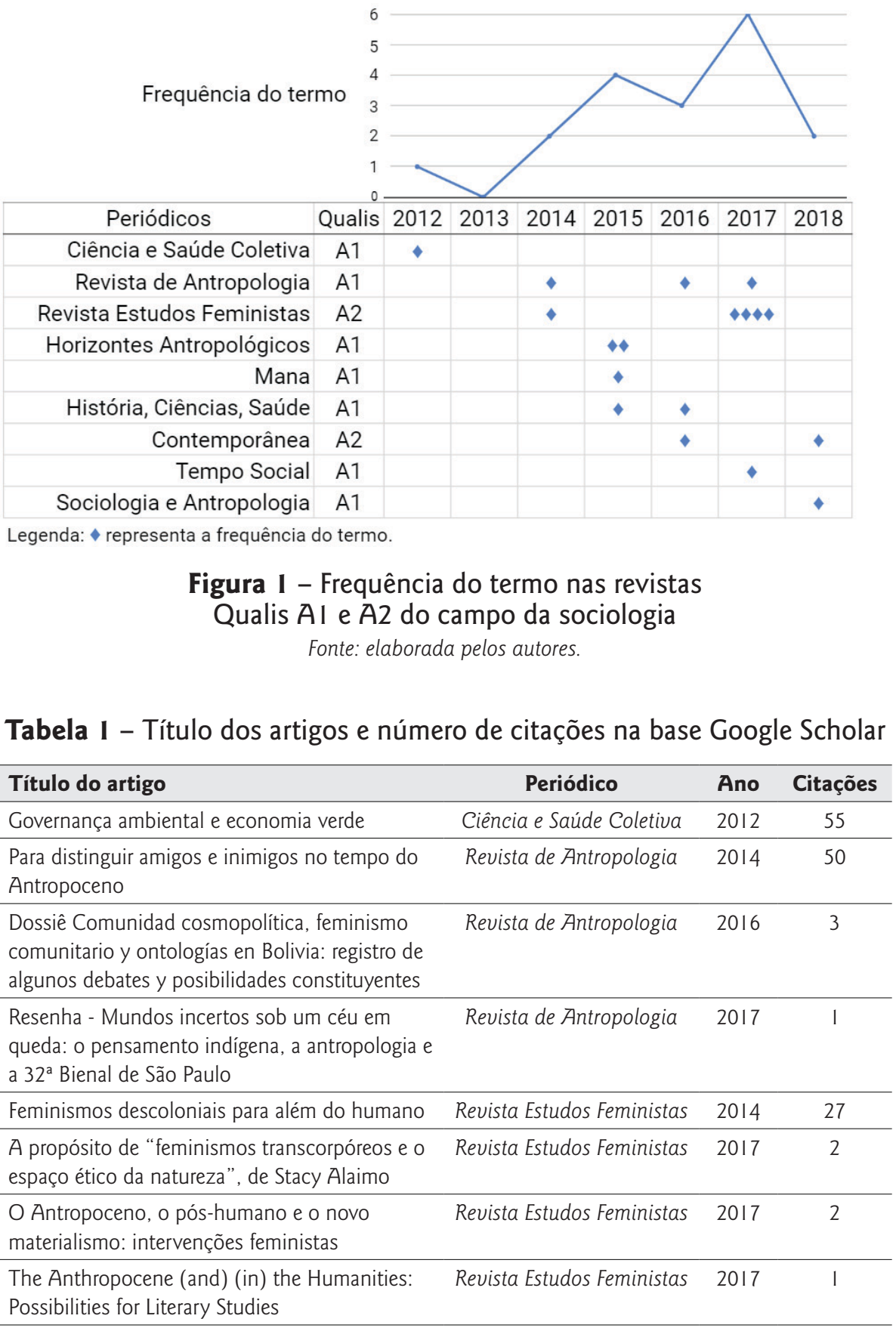




\begin{tabular}{|c|c|c|c|}
\hline Título do artigo & Periódico & Ano & Citações \\
\hline Editorial: segundo número do volume 25 de 2017 & Revista Estudos Feministas & 2017 & - \\
\hline $\begin{array}{l}\text { RESENHA SÜSSEKIND, Felipe. O rastro da } \\
\text { onça: relações entre humanos e animais no } \\
\text { Pantanal. }\end{array}$ & Horizontes Antropológicos & 2015 & I \\
\hline $\begin{array}{l}\text { RESENHA KOHN, Eduardo. How forests think: } \\
\text { toward an anthropology beyond the human. }\end{array}$ & Horizontes Antropológicos & 2015 & - \\
\hline Uma antropologia além de natureza e cultura? & $\begin{array}{c}\text { Mana } \\
\text { (Rio de Janeiro. On-line) }\end{array}$ & 2015 & 9 \\
\hline $\begin{array}{l}\text { A evolução do comportamento cultural } \\
\text { humano: apontamentos sobre darwinismo e } \\
\text { complexidade }\end{array}$ & História, Ciências, Saúde & 2015 & 2 \\
\hline $\begin{array}{l}\text { A nova história das ciências: entrevista com } \\
\text { Dominique Pestre }\end{array}$ & História, Ciências, Saúde & 2016 & 1 \\
\hline $\begin{array}{l}\text { Perspectivas tecnoxamânicas e tecnomágicas no } \\
\text { ativismo digital brasileiro recente: uma trajetória } \\
\text { possível }\end{array}$ & $\begin{array}{l}\text { Contemporânea - Revista } \\
\text { de Sociologia da UFSCar }\end{array}$ & 2016 & - \\
\hline $\begin{array}{l}\text { Ética ambiental no Brasil: história, campo de } \\
\text { estudos e militância: entrevista com Luciano } \\
\text { Félix Florit }\end{array}$ & $\begin{array}{l}\text { Contemporânea - Revista } \\
\text { de Sociologia da UFSCar }\end{array}$ & 2018 & - \\
\hline Mercados como espelho & Tempo Social (online) & 2017 & - \\
\hline $\begin{array}{l}\text { Copernicus in the amazon: ontological turnings } \\
\text { from the perspective of amerindian ethnologies }\end{array}$ & $\begin{array}{l}\text { Sociologia E } \\
\text { Antropologia }\end{array}$ & 2018 & 5 \\
\hline
\end{tabular}

Fonte: elaborada pelos autores.

No que tange à produção científica sobre mudanças climáticas em revistas nacionais de sociologia, o número, extremamente baixo, pode ser considerado ainda menor quando se analisam os artigos em separado. O artigo presente na revista Ciência e Saúde Coletiva (ISSN 1413-8123), editada pela Associação Brasileira de Saúde Coletiva (Abrasco), "Governança Ambiental e Economia Verde" (2012), não é um artigo propriamente do campo da sociologia, embora dialogue de forma transversal com o tema. O texto foi escrito no élan da Conferência Rio+20, em que os autores propóem uma reflexão para discutir que tipo de sustentabilidade está por trás da economia verde, a sua aplicabilidade e o que deveria ser priorizado na discussão de governança ambiental global. Ao longo do texto, o termo "Mudanças Climáticas" aparece com três registros, enquanto "Antropoceno" é mencionado duas vezes. 
Ambos os artigos de 2015 presentes na revista Horizontes Antropológicos (ISSN 0104-7183), publicada pelo Programa de Pós-Graduação em Antropologia Social da Universidade Federal do Rio Grande do Sul (UFRGS), são resenhas, não artigos, uma do livro $O$ rastro da onça: relaçóes entre humanos e animais no Pantanal (2015) e outra do livro How forests think: toward an anthropology beyond the human (2013). Outra resenha que figura entre a listagem dos artigos é a de Mundos incertos sob um céu em queda: o pensamento indígena, a antropologia e a 32a Bienal de São Paulo (2017), publicada na Revista de Antropologia (ISSN 1678-9857), publicação quadrimestral do Departamento de Antropologia da Faculdade de Filosofia, Letras e Ciências Humanas da Universidade de São Paulo (FFLCH/USP).

No artigo presente na revista História, Ciências, Saúde - Manguinhos, Rio de Janeiro (ISSN 0104-5970), "A evolução do comportamento cultural humano: apontamentos sobre darwinismo e complexidade" (2015), a menção ao antropoceno é brevemente destacada para caracterização da conjuntura contemporânea, não se caracterizando como um estudo sobre o tema ou que tenha o tema como interface da pesquisa.

No mesmo periódico, em 2016, a menção ao termo é um depoimento: "A nova história das ciências: entrevista com Dominique Pestre". De acordo com a revista, Pestre é físico e historiador referência para os estudos da história das ciências e das técnicas nas últimas décadas. Ao longo da entrevista, Pestre reflete sobre o papel das ciências e dos saberes no mundo contemporâneo e sobre as profundas relaçóes entre o conhecimento científico e o poder político e econômico, evidenciando a participação da sociedade nessa produção. O termo "antropoceno", como no outro artigo da própria revista, aparece novamente de forma tangencial, destacando uma conjuntura contemporânea, sem aprofundamento ou reflexão específica.

O artigo levantado no periódico Contemporânea, revista semestral do Departamento e do Programa de Pós-Graduação em Sociologia da Universidade Federal de São Carlos (UFSCar) (ISSN 2236-532X), "Ética ambiental no Brasil: história, campo de estudos e militância” (2018), é uma entrevista com Luciano Félix Florit. Na entrevista, tanto o conceito 
de antropoceno quanto o de mudanças climáticas são mencionados uma vez pelo entrevistado, também de forma conjuntural e pontual.

Em artigo no periódico Mana - Estudos de Antropologia Social (ISSN 1678-4944), de 2015, uma publicação organizada pelo Programa de Pós-Graduação em Antropologia Social do Museu Nacional, da Universidade Federal do Rio de Janeiro (UFRJ), o conceito de antropoceno e mudanças climáticas novamente é mencionado uma vez e de forma pontual.

Em "Dossiê Comunidad cosmopolítica, feminismo comunitario y ontologías en Bolivia: registro de algunos debates y posibilidades constituyentes" (2016), da Revista de Antropologia, há uma menção ao termo "antropoceno" com referência ao texto de Déborah Danowsky e Eduardo Viveiros de Castro, "Há mundo por vir? Ensaio sobre os medos e os fins" (2014). O artigo de Bruno Latour, "Para distinguir amigos e inimigos no tempo do Antropoceno" (2014), publicado no mesmo periódico, tem a marca de 50 citaçóes, de acordo com a base do Google Scholar, podendo ser indício de que o texto teve boa circulação e repercussão no campo. A discussão sobre o antropoceno é central à reflexão apresentada, com cerca de 20 mençóes ao termo. $\mathrm{O}$ artigo é originalmente uma palestra proferida pelo renomado sociólogo no Simpósio "Thinking the Anthropocene", na École d'Hautes Études en Sciences Sociales em Paris, em novembro de $2013^{8}$.

No periódico Sociologia e Antropologia (ISSN 2238-3875), publicação quadrimestral on-line do Programa de Pós-Graduação em Sociologia e Antropologia (PPGSA), do Instituto de Filosofia e Ciências Sociais (IFCS) da UFRJ, onde consta o artigo "Copernicus in the amazon: ontological turnings from the perspective of amerindian ethnologies" (2018), embora o termo "antropoceno" seja mencionado, esse não é o foco da pesquisa apresentada.

Em Tempo Social (ISSN 1809-4554), publicação do Departamento de Sociologia da FFLCH/USP, "Mercados como espelho" (2017), antropoceno não é o centro do artigo, verificando-se apenas uma menção.

8 A versão original pode ser acessada no site http://www.bruno-latour.fr/sites/default/files//3 I-an-thropocene-paris-11-13.pdf. 
O mesmo pode-se dizer em relação ao texto presente no periódico da revista Contemporânea, da UFSCar, "Perspectivas tecnoxamânicas e tecnomágicas no ativismo digital brasileiro recente: uma trajetória possível" (2016), com apenas uma mençáo pontual do termo "antropoceno" relacionando-o a uma caracterização da conjuntura atual.

Já a Revista Estudos Feministas (ISSN 1806-9584), publicação quadrimestral, sediada no Centro de Filosofia e Ciências Humanas (CFH) e no Centro de Comunicação e Expressão (CCE) da Universidade Federal de Santa Catarina (UFSC), foi o periódico que mais apareceu na listagem (Figura 1), com cinco artigos, embora, como já se tinha dito, um deles seja o editorial da edição 2017.

Ao se olhar mais de perto os artigos desse periódico, percebe-se que o artigo "Feminismos descoloniais para além do humano" (2014), apesar de citar o termo, não tem como foco o antropoceno ou as mudanças climáticas, embora aponte pistas futuras sobre se, para a nova fase dos feminismos descoloniais, estaria se iniciando uma fase do feminismo do antropoceno. Já em "The Anthropocene (and) (in) the Humanities: Possibilities for Literary Studies" (2017), a discussão sobre mudanças climáticas e o antropoceno é central ao texto, buscando desvendar a genealogia do termo, a mediação entre um conceito que vem das ciências geológicas e conquista espaço nas ciências sociais, assim como se propóe a relacionar as novidades trazidas pela época do antropoceno para os estudos literários. Da mesma forma, no artigo "O Antropoceno, o pós-humano e o novo materialismo: intervençóes feministas" (2017), novamente o termo ganha o centro da reflexão proposta pelas autoras.

Em "A propósito de 'feminismos transcorpóreos e o espaço ético da natureza’, de Stacy Alaimo" (2017), o foco não é antropoceno ou as mudanças climáticas, mas o lugar do feminismo, ou do ecofeminismo, bem como sua relaçáo com o espaço da natureza.

Ao excluirmos dos 18 artigos selecionados as três resenhas e as duas entrevistas, restam-nos 13 artigos. Desses, apenas três refletem sobre e têm por objetivo e foco central a discussão das mudanças climáticas e da época do antropoceno: "Para distinguir amigos e inimigos no tempo do Antropoceno", na Revista de Antropologia, "The Anthropocene (and) (in) the 
Humanities: Possibilities for Literary Studies" (2017) e "O Antropoceno, o pós-humano e o novo materialismo: intervençôes feministas" (2017), na Revista Estudos Feministas.

\section{Mudanças climáticas e mobilização social no Brasil}

A grande repercussão da "Greve Mundial pelo Clima” é um exemplo de como a preocupação em torno dos problemas das mudanças climáticas está ganhando proporçôes. Os eventos que compuseram a greve na semana de 20 a 27 de setembro de 2019, enquanto ocorria a Cúpula do Clima em Nova Iork, aconteceu concomitantemente em 185 países e mobilizou mais de 7,6 milhóes de pessoas. As informaçôes foram tiradas do site Global Climate Strike 9 , que reúne as informaçôes relacionadas à greve mundial pelo clima em todo o mundo, em parceria com diversos outros portais. Os mapas a seguir apresentam a participação da população na greve do clima por país, em número absoluto de participantes (Figura 2) e em proporção de participantes em relação à população total do país correspondente (Figura 3).

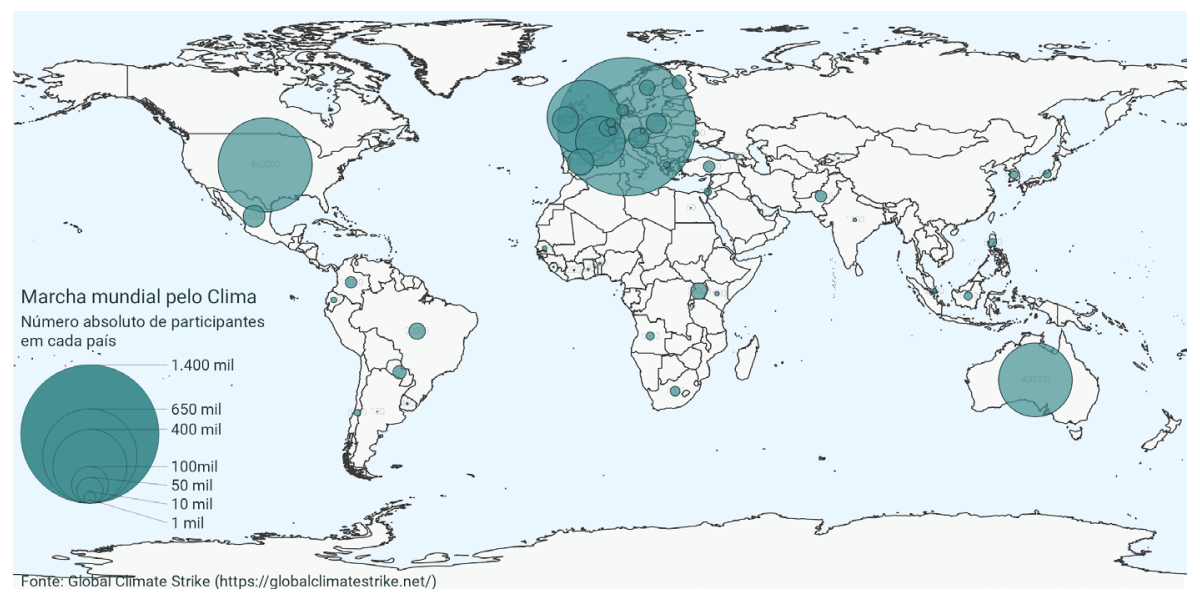

Figura 2 - Participação da população na greve do clima por país, em número absoluto de participantes

Fonte: elaborada pelos autores.

9 Disponível em: https://globalclimatestrike.net/. Acesso em: 30 out. 2019. 


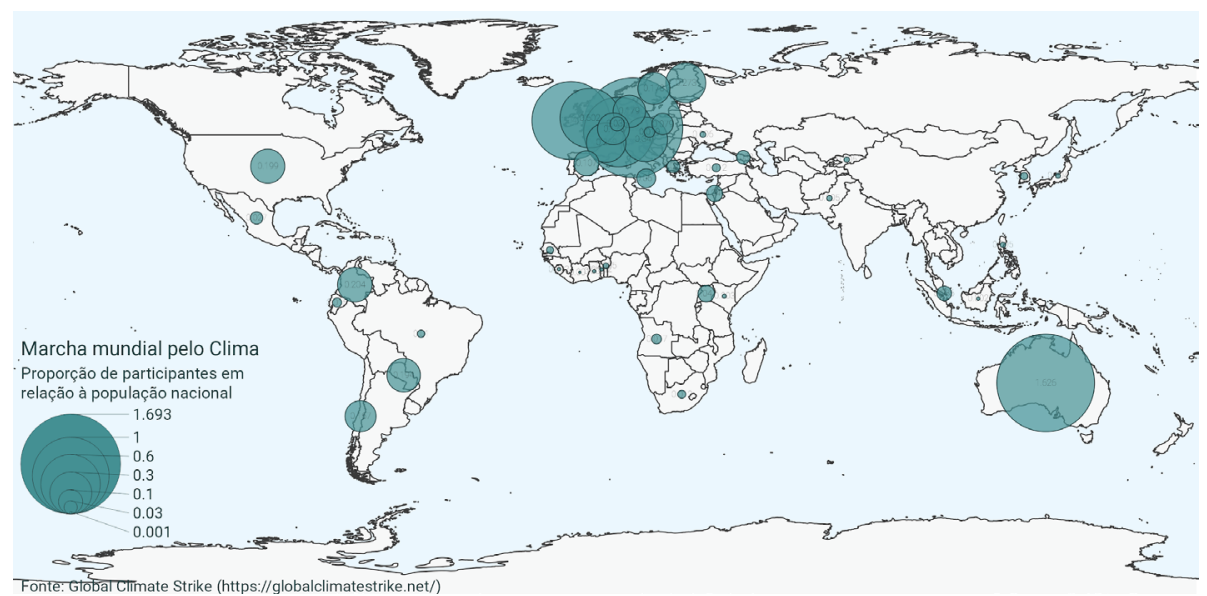

Figura 3 - Participação da população na greve do clima por país, em proporção de participantes em relação à população total do país Fonte: elaborada pelos autores.

Analisando essas representaçóes, salta aos olhos a discrepância entre as mobilizaçóes no Norte e no Sul Global, tanto em números absolutos quanto proporcionalmente. Só na Alemanha, país que mobilizou mais pessoas em torno dos eventos da Greve do Clima, estima-se 1,4 milhão de pessoas (aproximadamente 1,6\% da população do país). Os Estados Unidos, país que estava sediando a Cúpula do Clima, reuniu 650 mil pessoas nos protestos, aproximadamente $0,2 \%$ da população. No Brasil, a estimativa de participação foi de 20 mil pessoas, o que representa menos de $0,01 \%$ da população. Em relação a outros países da América do Sul, como Paraguai (com 13,2 mil participantes; 0,19\% da população nacional), Colômbia (10 mil; 0,2\%), Chile (3 mil; 0,17\%), Equador (2,5 mil; 0,15\%) e Uruguai $(400 ; 0,12 \%)$, o Brasil foi o que teve maior mobilização em números absolutos de participantes, porém, proporcionalmente à população total do país, foi o menos expressivo, ficando atrás apenas da Argentina $(100 ; 0,0002 \%)$.

Esses protestos mundiais foram inspirados no movimento \#FridaysForFuture (Sextas-feiras para o futuro), iniciado pela jovem sueca Greta Thunberg, que tem recebido um protagonismo quando se trata de movimentos populares em torno das mudanças climáticas, principalmente em 
países do Norte Global. Além disso, a mobilização de Greta influencia diretamente na alta adesão de jovens e crianças, que, também no Brasil, foram maioria nas manifestaçôes.

As manifestaçóes de 20 a 27 de setembro de 2019 no Brasil ocorreram em praticamente todas as capitais, com destaque para São Paulo (SP), Rio de Janeiro (RJ) e Brasília (DF), e mais algumas cidades do interior de SP e outros estados. Fazendo uma análise sobre as reportagens e materiais jornalísticos produzidos por diversas mídias e portais ${ }^{10}$ do país a respeito das manifestaçôes, vê-se a maioria das pessoas como classe média, brancas e jovens. A maior parte das faixas e cartazes expressava demandas relacionadas ao consumo de plástico, preservação da natureza e queimadas na Amazônia, junto com algumas críticas ao Governo Federal e ao Ministério do Meio Ambiente também em relação à Amazônia. Também não recebe destaque a participação de outros movimentos sociais, que não ambientalistas, ou de sindicatos e partidos políticos (com exceção de uma menção ao Partido Socialismo e Liberdade - PSOL). O tema da "Justiça Climática”, comum ao material verificado nas marchas no Norte Global, não pôde ser percebido nas manifestaçóes de setembro no Brasil.

\section{Mudanças climáticas, mobilização social e pontos de inflexão}

Do outro lado do Atlântico, na Europa, os europeus afirmam estar muito preocupados com as mudanças climáticas e apoiam açóes em toda a União Europeia (UE) para combatê-las, de acordo com uma recente pesquisa Eurobarometer da Comissão Europeia (EUROBARÓMETRO..., 2019). Segundo dados da pesquisa, $93 \%$ dos cidadãos da UE consideram as alteraçôes climáticas um problema grave e $79 \%$ consideram-nas um problema muito grave, enquanto $92 \%$ dos entrevistados pensam que é importante que o governo nacional estabeleça metas ambiciosas para aumentar a quantidade de energia renovável usada e $89 \%$ acreditam que os governos devem fornecer apoio para melhorar a eficiência energética até 2030.

10 Jornais Estadão, Folha de S.Paulo, GI, Brasil de Fato, El País, Exame, Agência Brasil - EBC, Rede Brasil Atual, Blog Greenpeace, Fridays for Future Brasil. Acesso em: 15 jan. 2020. 
Ainda de acordo com a pesquisa, $84 \%$ dos participantes acreditam que mais apoio financeiro público deve ser dado à transição para energias limpas, mesmo que isso signifique reduzir os subsídios aos combustíveis fósseis.

Se a esfera política vive da aceitação de presentes e futuros eleitores, a ordem política democrática depende da aceitação da população em geral. Agora que os protestos públicos revelam prontidão social para aceitar medidas ambiciosas de política climática para mitigar as mudanças climáticas, não há justificativa política para não agir, mesmo que governos, partidos ou movimentos céticos ao aquecimento global ainda duvidem dos dados climáticos e seus impactos.

Mas os movimentos cívicos climáticos têm o potencial de influenciar agendas políticas ou de produção de saberes? Existem exemplos empíricos de que, nas esferas social, econômica e tecnológica, pequenas parcelas da populaçáo ou usuários podem mudar o padrão dominante de comportamento ou norma. Elementos de mobilização social podem ser definidos como subdomínios do sistema socioecológico planetário; o ponto de inflexão é o limiar crítico no qual ocorrem os fenômenos do regime ou transformaçóes rápidas na estrutura e função dos sistemas socioecológicos. Elementos representativos de mobilização social para subsistemas socioeconômicos específicos podem ser desencadeados por intervençôes de mobilização social. Os pontos de inflexão social podem influenciar as mudanças climáticas (KOPP et al., 2016).

Pontos de inflexão social positivos têm o potencial de desencadear a mudança de indivíduos ou sistemas coletivos necessária para criar sociedades que almejam uma transiçáo a uma economia de baixo carbono. O processo de denúncia social marca um ponto no tempo em que uma pequena mudança em um sistema modifica todo o sistema qualitativamente, em seu estado, em algum momento no futuro.

Cada elemento de mobilização social possui diferentes intervençóes da sociedade, assumindo que a ativação de várias intervençôes aumenta as chances de atingir uma meta previamente estabelecida. A questão principal no caso brasileiro é o inverso, porque os efeitos e os impactos das mudanças climáticas, que aqui tendem a atingir as populaçóes mais pobres 
e vulneráveis, não ativam mobilizaçôes sociais com impacto imediato suficiente para a reivindicação de direitos, ou mesmo de interesse acadêmico no campo da sociologia.

Como apontado pelo Eurobarómetro (2019), pesquisas de opinião pública indicam que um número crescente de cidadãos em vários países estáo seriamente preocupados com as mudanças climáticas. No entanto, ainda existe uma lacuna de conscientização e ação. A pesquisa não considera o Acordo de Paris, por exemplo, como um ponto de inflexáo positivo ou uma visão que possa desencadear o desenvolvimento de capacidades que levem a uma mudança.

O movimento da Greve Climática aquece o debate público sobre as mudanças climáticas e as geraçóes intergeracionais. Justiça e demanda por ação podem ser os pontos de inflexáo social desse processo, quando pequenas tendências em comportamento, valor ou mudança normativa ou tecnologia tornam-se um padráo importante. $\mathrm{O}$ ativismo climático é uma forma contemporânea de engajamento cívico, envolvendo e mobilizando muitos jovens em ativismo, que, por sua vez, frequentemente envolvem seus próprios pais.

Dubois et al. (2019) analisaram o movimento Fridays For Future, em que muitos dos membros acreditam que seus protestos causarão mudanças e que mudar o próprio comportamento e consumo é relevante para combater as mudanças climáticas. Uma pista para o abismo entre o engajamento e a mobilização social entre países do Sul e do Norte Global para a agenda da ação climática são as diferenças sociais e a urgência de pautas prioritárias, como desigualdade social. Outro ponto importante, que merece ser explorado em pesquisas futuras, pode ser o porquê de movimentos e organizaçóes sociais brasileiras não terem assumido a agenda da Justiça Climática, que, de alguma maneira, poderia integrar questóes relacionadas ao estudo dos impactos das mudanças climáticas e à reduçáo das desigualdades (TORRES et al., 2020; MILANEZ; FONSECA, 2011).

Schlosberg e Collins (2014), ao remontarem às origens dos movimentos por Justiça Climática, veem vestígios de uma passagem dos movimentos por justiça ambiental para os por justiça climática. Refazendo esse percurso, fica evidente como essa passagem ocorreu com base em experiências 
de grupos radicados nos Estados Unidos e, depois, na Europa. Nesse sentido, pode estar aí um pilar essencial para se entender como as manifestaçôes globais pelo clima se espalharam mais pelos países do Norte Global.

A Conferência de Cochabamba sobre Mudanças Climáticas, em 2010, foi um ponto de inflexão importante para parte do Sul Global, mais detidamente a América Latina, em relação ao tema. Sob a organização do presidente Evo Morales e seu vice, Garcia Linera, a Bolívia sediou o encontro que tinha como objetivo reunir movimentos sociais e aqueles que se sentiam excluídos do processo oficial da ONU sobre o Clima (UNFCCC), após o fracasso das negociaçóes de Copenhague, na COP-15, e a diminuição dos espaços formais de participação da sociedade.

Nota-se que, a partir de Cochabamba, uma produção intelectual latino-americana, sobretudo da América ibérica, sobre o tema da justicia climatica, embora incipiente, começa a figurar em periódicos acadêmicos (TORRES et al., 2020). A maior diferença, no entanto, trazida por Cochabamba e reverberada nessa produção intelectual para as demandas de grupos sociais que advogam por justiça climática no Global Norte, é a necessidade de se mudar o sistema capitalista e seu modo de produçáo econômico. Evidentemente, não se trata das mesmas aspiraçôes de organizaçóes internacionais, como a própria ONU e o Painel Intergovernamental sobre Mudanças Climáticas (IPCC), que já incluem o termo "Justiça Climática" em seus documentos, o mesmo de organizaçóes náo governamentais internacionais, como ICLEI, Greenpeace ou WRI.

As dimensões culturais das mudanças climáticas são abordagens ainda pouco estudadas (ADGER et al., 2013). Se identidade e pertencimento são elementos do campo simbólico fundamentais para a tomada de consciência e ação, a ausência de uma agenda sobre mudanças climáticas, menos ainda uma agenda por justiça climática, pode dar sugestóes sobre o atual estágio da conjuntura brasileira. Trata-se, portanto, de um movimento distinto do que se observa, por exemplo, em relação à proteção da Amazônia, em que foi produzido um sentimento de identidade e pertencimento sobre a floresta - manifestaçóes pró-Amazônia reuniram milhôes de pessoas no Brasil no início de 2019. Há pistas de uma relação cíclica, ou que se retroalimenta, entre o que se produz de saber, conhecimento tradicional ou acadêmico, 
e o engajamento das ruas, espontâneo ou potencializado por agendas de movimentos, ONGs de elite ou mesmo organizaçóes governamentais.

No Brasil, como mostram Milanez e Fonseca (2011), ainda não é feita a relação entre uma tragédia e um evento climático extremo, nem por seus moradores, nem pelo governo ou mídias. Voltando novamente à comparação com as queimadas da floresta amazônica - sabendo-se das diferenças entre escalas, interesse internacional, ciclos naturais e conflitos ambientais no território -, o tema dos incêndios rapidamente foi associado aos riscos que a perda ecológica significaria à agenda do combate às mudanças climáticas.

O que se perde com uma tragédia climática, entre bens materiais e não materiais, ou a perda de costumes culturais, pode ser enorme. Porém, ao não associar o acontecimento às mudanças climáticas, não haverá possibilidade de criação de uma arena de entendimento e reflexão sobre o ocorrido, o que, em última instância, representa a não criação identitária e a sensaçáo de pertencimento mínimo necessário ao engajamento e mobilização social. O curioso, para nosso caso, é como estamos tratando de dois temas com pequena adesão. Tanto a pauta das ruas sobre a agenda climática é pequena, quanto a produçáo sobre ela no Brasil é lacônica.

O mesmo ocorre na esfera da política pública, como observam Di Giulio et al. (2018), que, analisando o caso da cidade de São Paulo, percebem que o debate sobre mudança climática acontece "às escondidas", por trás de termos como "desenvolvimento sustentável" e "economia verde", assim como o fato de que as políticas existentes para o setor náo conseguem ser implementadas, pois existe o engajamento de diversos atores e stakeholders na sua elaboração, mas não em etapas posteriores. Os autores ainda observam que, na cidade, o "nível de interação entre cientista e tomadores de decisão é baixo, especialmente em relação à ciência e à ação do clima” (DI GIULIO et al., 2018, p. 5).

A agenda climática no Brasil, sobretudo do ponto de vista das políticas públicas (BARBI, 2015), reflete e faz refletir essa baixa interação entre a ciência e a ação do clima. Esse processo explica, em parte, a dificuldade em se formar uma comunidade epistêmica para atuar nessa área específica do conhecimento, fortalecendo a figura a que aqui se está recorrendo, do 
Semeador, o não especialista. Quantos técnicos capacitados para lidar com cenários e planejamento antecipatório às mudanças climáticas podem ser encontrados nos diversos níveis de governo pelo país? Como está o processo de formação desses profissionais em cursos técnicos, universitários ou de extensão? A formação de especialistas para uma nova área de conhecimento, necessariamente interdisciplinar, sobretudo uma área que trabalha com complexidade e incertezas, é um processo de longa duração.

É preciso deixar claro, por outro lado, que a ausência de um corpo de especialistas não significa que o trabalho não venha sendo feito, mesmo que de forma isolada. Ao contrário, vale destacar o trabalho da Defesa Civil em atuar na linha de frente dos impactos dos eventos severos no território (IWAMA et al., 2016).

\section{Comentários finais}

O que se observa, portanto, é que a produção no campo da sociologia em periódicos brasileiros sobre clima/antropoceno é muito restrita e que, inclusive ao se aprofundar a leitura de alguns artigos, vários deles dialogam de forma transversal com o tema"l. A sociologia tem entrado tardiamente no debate ambiental - embora perceba-se crescimento no interesse pelo tema por parte de jovens pesquisadores, assim como por centros de excelência no país, como o Núcleo de Estudos e Pesquisas Ambientais (Nepam/Unicamp), entre outros departamentos abertos à sociologia ambiental. No entanto, é cada vez mais relevante sua presença no debate acadêmico, pois o maior desafio é a articulação do tema como diálogo interdisciplinar. A reflexão sociológica tem um grande potencial de debate em torno das transformaçóes na gestáo e nas mudanças no comportamento, o grande calcanhar de Aquiles. A abordagem sociológica abre um estimulante espaço de reflexão para compreender melhor o papel dos diversos aspectos sociais que podem fortalecer um maior envolvimento social e participação da sociedade.

Por outro lado, o artigo apresentou o caráter ainda restrito da participação social nos países do Sul. Observa-se que as mobilizaçôes pelo clima

I I Vale o registro de que, durante a elaboração da presente pesquisa, foi publicado um dossiê especial (v. 2I, n. 5I) na renomada revista Sociologias (ISSN 1807-0337), com sete artigos que versam sobre o tema das mudanças climáticas, ciência e sociedade. 
têm tido presença maior de jovens, na sua maioria de classe média e de algumas organizaçóes de jovens com baixa representatividade em segmentos populares e bairros da periferia, ou de comunidades tradicionais. O que se verifica é um alcance muito limitado e pouco reflexivo, se comparado às manifestaçốes nos países do Norte, ou seja, esvaziado de uma crítica social a partir do contexto do Sul Global, onde caberiam, por exemplo, pautas decoloniais por justiça climática e a leitura interdisciplinar das problemáticas ambientais (como as mudanças climáticas) e sociais (desigualdade, conflito etc.).

Conclui-se argumentando que, enquanto persistirem as desigualdades na América Latina e nos outros territórios do Sul Global, o chamado à ação contra as mudanças climáticas deve ser, sobretudo, contra as desigualdades ambientais. O espírito do Semeador, aventureiro e espontâneo, continua a ser o espectro a rondar a agenda política das mudanças climáticas no Brasil contemporâneo. É, ao mesmo tempo, produto e produtor, que reflete e faz refletir, de forma dialética, a agenda ambiental e a formação de seu corpo orgânico de intelectuais preparados à ação e aos desafios do século XXI.

\section{Referências}

ADGER, W. N.; ARNELL, N. W.; TOMPKINS, E. L. Successful adaptation to climate change across scales. Global Environmental Change, v. 15, n. 2, p. 77-86, 2005.

ADGER, W. N. et al. Cultural dimensions of climate change impacts and adaptation. Nat. Clim. Change 3, p. 112-117, 2013.

AMBRIZZI, T. et al. Atribuição de causas da variabilidade e extremos climáticos. In: NOBRE, C. A.; MARENGO, J. A. (org.). Mudanças climáticas em rede: um olhar interdisciplinar. São José dos Campos: Canal 6 Editora, 2017. v. 1, p. 69-96.

BARBI, F. Mudanças climáticas e respostas políticas nas cidades. Campinas: Editora da Unicamp, 2015. v. 1, 246 p.

BARBI, F; FERREIRA, L. C. Climate change in brazilian cities: policy strategies and responses to global warming. International Journal of Environmental Science and Development, v. 4, p. 49-51, 2013.

BECK, U. Metamorfoses do Mundo. Rio de Janeiro: Zahar, 2018.

BRULLE, R.; RILEY, E. D. Sociology and Climate Change. In: DUNLAP, R. E.; BRULLE, R. J. Climate Change and Society: Sociological Perspectives. New York: Oxford University Press, 2015. 
Nem leigos nem peritos: o semeador e as mudanças climáticas no Brasil | Pedro Henrique Campello Torres, Pedro Roberto Jacobi, Ana Lia Leonel

COATES, R. Citizenship-in-nature? Exploring hazardous urbanization in Nova Friburgo, Brazil. Geoforum, v. 99, p. 63-73, 2019.

DI GIULIO, G. M. et al. Mainstreaming climate adaptation in the megacity of São Paulo, Brazil. Cities, v. 72, p. 237-244, 2018.

DUBOIS, G. et al. It starts at home? Climate policies targeting household consumption and behavioral decisions are key to low-carbon futures. Energy Res. Soc. Sci., v. 52, p. 144-158, 2019. EUROBARÓMETRO SONDAGENS DE OPINIÃO DO PARLAMENTO EUROPEU. 2019. Disponível em: https://www.europarl.europa.eu/at-your-service/pt/be-heard/eurobarometer. Acesso em: 15 jan. 2020.

FERREIRA, L. da C. Idéias para uma Sociologia da questão ambiental - teoria social, sociologia ambiental e interdisciplinaridade. Desenvolvimento e Meio Ambiente (UFPR), Curitiba, v. 10, p. 77-89, 2004.

GLOBAL CLIMATE STRIKE. Disponível em: https:/globalclimatestrike.net/7-million-peopledemand-action-after-week-of-climate-strikes/. Acesso em: 30 out. 2019.

HOLANDA, S. B. Raízes do Brasil. São Paulo: Cia. das Letras, 2006.

IWAMA, A. Y. et al. Risco, vulnerabilidade e adaptação às mudanças climáticas: uma abordagem interdisciplinar. Ambient. Soc., São Paulo, v. 19, n. 2, p. 93-116, 2016.

JACOBI, P. Poder local, políticas sociais e sustentabilidade. Saúde Soc., v. 8, n. 1, p. 31-48, 1999.

JACOBI, P. R. et al. Water governance and natural disasters in the Metropolitan Region of São Paulo, Brazil. International Journal of Urban Sustainable Development, v. 5, p. 1-12, 2013.

JACOBI, P. R.; MOMM-SCHULT, S. I.; BOHN, N. Ação e reação. Intervenções urbanas e a atuação das instituições No Post Desastre em Blumenau (Brasil). EURE (Santiago. En línea), v. 39, p. 243/116-261, 2013.

KINGDON, J. Agendas, alternatives, and public policies. New York: HaperCollins College, 1995.

KOPP, R. E. et al. Tipping elements and climate-economic shocks: pathways toward integrated assessment. Earth's Future 4, p. 346-372, 2016.

MARCELINO, E. V. et al. Impacto do Furacão Catarina sobre a regiáo sul catarinense: monitoramento e avaliaçáo pós-desastre. Geografia, v. 30, n. 3, p. 559-582, 2005.

MARRIS, E. Why young climate activists have captured the world's attention. Nature 573, p. 471472, 18 Sept. 2019.

MILANEZ, B.; FONSECA, I. F. F. Justiça climática e eventos extremos: uma análise da percepção social no Brasil. Revista Terceiro Mundo, v. 1, n. 2, p. 82-100, 2011. 
NOGUEIRA, F. R.; CANIL, K. Avanços e limitações: reflexôes sobre a gestão de risco. In: SULAIMAN, S. N.; JACOBI, P. R. (org.). Melhor prevenir: olhares e saberes para a redução de risco de desastre. São Paulo: IEE-USP, 2018. v. 1, p. 49-56.

RISÉRIO, A. Cidades do Brasil. Rio de Janeiro: Editora 34, 2012.

SCHMIDT, L.; GOMES, C.; JACOBI, P. R. Saberes interdisciplinares para adaptação: comunidades, academia e meio ambiente. In: TORRES, P. et al. (org.). Governança e planejamento ambiental: adaptação e políticas públicas na Macrometrópole Paulista. Rio de Janeiro: Letra Capital, 2019. v. 11, p. $152-160$.

SCHLOSBERG, D.; COLLINS, L. B. From Environmental to climate justice: climate change and the discourse of environmental justice. Wiley Interdisciplinary reviews: Climate Change, 2014.

SULAIMAN, S. N.; ALEDO, A. Desastres naturais: convivência com o risco. Estudos Avançados (Online), v. 30, p. 11-23, 2016.

TORRES, P. H. C. et al. Is the Brazilian National Climate Change Adaptation Plan addressing inequality? Climate and Environmental Justice in a Global South perspective. Environmental Justice, 2020.

TRAVASSOS, L. R. F. C. et al. Why do extreme events still kill in the São Paulo Macrometropolis (SPMM)? Chronicle of a Death Foretold in the Global South. International Journal of Urban Sustainable Development, 2020.

UITTO, J. I., VAN DEN BERG, R. D.; PURI, J. Evaluating Climage Change Action for Sustainable Development. Springer, 2017.

URRY, J. Sociology and Climate Change. The Sociological Review, v. 57, p. 84-100, 2009.

VIOLA, E.; BASSO, L. O Sistema Internacional no Antropoceno. Revista Brasileira de Ciências Sociais, v. 31, n. 92, p. 1-18, out. 2016.

VEIGA, J. E. da. O Antropoceno e a ciência do sistema terra. Sáo Paulo: Editora 34, 2019.

YEARLEY, S. Sociology and Climate Change after Kyoto: What Roles for Social Science in Understanding Climate Change? Current Sociology, v. 57, n. 3, p. 389-405, 2009.

Recebido: 28/01/2020

Aceito: 05/04/2020 


\section{Neither laymen nor experts: the sower and climate change in Brazil}

\section{Abstract}

The climate change agenda and its relationship with social struggles and mobilizations has grown in recent decades on a global scale. In the sociological field, the topic has received increasing interest, both in its scientific production and in social engagement. Based on a literature review of Brazilian sociological production in national journals, we sought to verify how this process is underway in Brazil. Then, seeking to analyze the relationship between scientific production and streets mobilization, we analyzed the climate strike demonstrations that took place in September 2019 in a comparative perspective. Both academic production and social mobilization were extremely unrepresentative in the analyzed case.

Keywords: Climate change. Anthropocene. Climate strike. Fridays for future. Climate justice. 